\title{
Performance analysis of two-stage pressure retarded osmosis
}

\author{
Suksun Amornraksa ${ }^{1}$, Kanokporn Youyen ${ }^{2}$, and Lida Simasatitkul ${ }^{2, *}$ \\ ${ }^{1}$ The Sirindhorn International Thai-German Graduate School of Engineering (TGGS) King Mongkut's University of Technology \\ North Bangkok, 10800 Thailand \\ ${ }^{2}$ Department of Industrial Chemistry, Faculty of Applied Science, King Mongkut's University of Technology North Bangkok, 10800 \\ Thailand
}

\begin{abstract}
The performance of a two-stage pressure retarded osmosis (PRO) for power generation with a total membrane length of 1 meter was investigated and analyzed in this work. Two feed configurations of freshwater and seawater were studied: one with the freshwater entering at the first stage only and the other with freshwater entering at both stages. The effect of membrane length and flow ratio between freshwater and seawater on the PRO performance were also examined. The results revealed that the performances of both feed configurations were quite similar. The membrane with a shorter length offered a higher average power density than that of a longer length. It was also revealed that the flow ratio had a strong influence on the average power density produced. The maximum average power density of $10.15 \mathrm{~W} / \mathrm{m}^{2}$ was obtained at the applied hydraulic pressure of 12 bar, the flow ratio of 5, and the membrane length of both stages of 0.5 meter. The best water utilization was achieved at $65 \%$.
\end{abstract}

Keyword. Two-stage pressure retarded osmosis, power density, water utilization, performance analysis, modelling

\section{Introduction}

Electricity demand is continually increasing because it is essential for household and industrial activities. The undesirable electricity from fossil fuels like coal leads to a search for renewable and clean energy such as wind, solar, and hydropower. Pressure retarded osmosis (PRO) is one of the latest renewable energy that has been developed. Electricity is generated from the difference between the salinity concentration of two fluids. In the PRO, a low salinity fluid, e.g., freshwater, permeates across a selective membrane to the other side where a high pressurized and high salinity fluid, e.g., seawater, flows to generate electricity [1].

Many studies tried to improve the efficiency of PRO through membrane characteristics by developing new membrane materials $[2,3]$. Other studies tried to investigate operating conditions, water resources, and membrane module design [4]. It is well-accepted that the optimal applied hydraulic pressure should be about half of the osmotic pressure. Although a large amount of energy can be harvested when mixing between freshwater and seawater, the actual harvested energy is limited due to internal concentration polarization (ICP) and external concentration polarization (ECP). So, thinfilm composite membranes have been developed to reduce the effect of ICP and ECP. They can provide high water permeability and produce a power density of 6 $\mathrm{W} / \mathrm{m}^{2}$ or higher [5].

Generally, a design of the PRO module is performed by using a single-stage operation. Naguib et al. [6] found that the power density is lost along the membrane length since thin-film of draw concentration is covered on the support layer of the membrane. He et al. [7] also proposed two-stage PRO configurations and compared with the single-stage PRO. The distribution of feed flow rate and membrane area were important factors to average power density. Multistage PRO (10-stage PRO) increased net power density around 9\% higher than a single-stage PRO with the same membrane area [8]. Thus, a two-stage PRO is proposed to reduce this effect and improve the overall performance in terms of power density. In addition, there is no need for an extra pump for the second-stage PRO. Two-stage PRO can also reduce the water requirement in the fresh feed stream. Thus, this work proposes two configurations of two-stage PRO. The effect of parameters such as flow ratio between draw solution and feed solution, applied hydraulic pressure, the fresh feed ratio to feed each stage, the flow ratio of draw solution and feed solution $\left(\mathrm{Q}_{\mathrm{D}} / \mathrm{Q}_{\mathrm{F}}\right)$, and membrane length in each stage was investigated in terms of power density and water utilization.

\section{Methodology}

Mathematical modeling of two-stage PRO consisting of osmotic pressure, water flux, salt flux, power density, and concentration was performed using MATLAB. Because water flux and salt flux equations are differential equations, Euler's method was used to solve

\footnotetext{
* Corresponding author: lida.s@sci.kmutnb.ac.th
} 
the differential equation. Osmotic pressure is determined by Van't Hoff equation as shown in eq (1).

$\pi=i C R T$

Power density is shown in eq. (2)

$W=J_{w} \Delta P$

Water flux is defined in eq. (3)

$J_{w}=A(\Delta \pi-\Delta P)$

Salt flux is defined in eq. (4)

$J_{s}=B \Delta c_{m}$

The effective concentration is defined in eq. (5)

$\Delta c_{m}=\frac{C_{D, b} \exp \left(\frac{-J_{w} \delta_{D}}{D}\right)-C_{F, b} \exp \left(\frac{J_{w}\left(\delta_{F}+S\right)}{D}\right)}{1-\frac{B}{J_{w}} \exp \left(\frac{-J_{w} \delta_{D}}{D}\right)+\frac{B}{J_{w}} \exp \left(\frac{J_{w}\left(\delta_{F}+S\right)}{D}\right)}$

Film thickness and mass transfer coefficient is defined in eq. (6) - (9).

$\delta_{F}=\frac{D}{K_{F}}$

$\delta_{D}=\frac{D}{K_{D}}$

$K_{F}=1.62\left(\frac{u_{F} D^{2}}{d_{h, F} L}\right)^{1 / 3}$

$K_{D}=1.62\left(\frac{u_{D} D^{2}}{d_{h, D} L}\right)^{1 / 3}$

Mass balance of draw solution and feed solution is performed in eq. (10) - (13).

$$
\begin{aligned}
& \frac{d Q_{D}}{d x}=J_{w}\left(A_{r}\right) \\
& \frac{d Q_{F}}{d x}=-J_{w}\left(A_{r}\right) \\
& \frac{d\left(Q_{D} C_{D}\right)}{d x}=J_{S}\left(A_{r}\right) \\
& \frac{d\left(Q_{F} C_{F}\right)}{d x}=-J_{S}\left(A_{r}\right)
\end{aligned}
$$

\section{Process description}

\subsection{Configuration 1: two-stage PRO in series without new feed solution at inter-stage}

Two-stage PRO is arranged in a series, as shown in Fig.1. The total membrane length of the two modules is 1 meter. Draw solution (seawater) is pressurized by a pressure exchanger and fed into the first membrane module. Feed solution enters the module at a pressure 1 bar. Because the draw solution has a high salinity, the feed solution permeates the membrane, resulting in seawater dilution. After that, the outlet streams from the first module enter the second module. A partial stream of outlet draw solution is sent to the pressure exchanger.

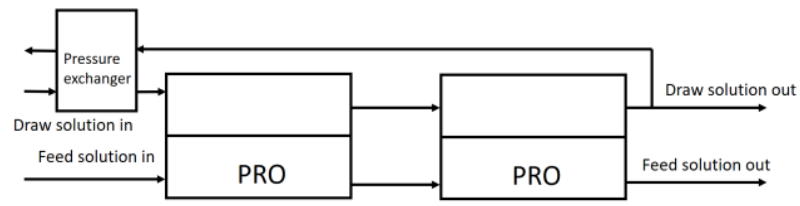

Fig. 1. Configuration 1 of two-stage PRO

\subsection{Configuration 2: two-stage PRO in series with feed solution at inter-stage}

The second configuration is very similar to the first configuration. However, the feed solution is split into two streams. The first stream is sent to the first module, while the second is sent to the second module. The input data used for both configurations is shown in Table 1 .

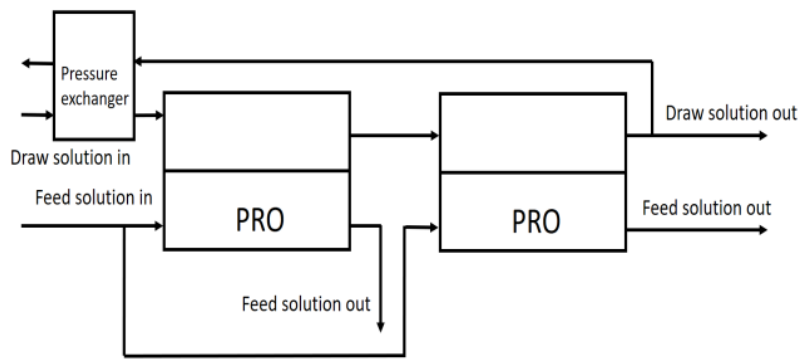

Fig. 2. Configuration 2 of two-stage PRO

Table 1. Input parameter of two-stage PRO [6]

\begin{tabular}{|c|c|}
\hline Parameter & Condition \\
\hline Feed concentration $(\mathrm{g} / \mathrm{l})$ & 0 \\
\hline Draw concentration $(\mathrm{g} / \mathrm{l})$ & 30 \\
\hline Temperature $\left({ }^{\circ} \mathrm{C}\right)$ & 25 \\
\hline Radius of hollow fiber $(\mathrm{m})$ & $0.1 \times 10^{-3}$ \\
\hline Radius of module casting $(\mathrm{m})$ & $0.15 \times 10^{-3}$ \\
\hline Water permeability $\left(\times 10^{-8} \mathrm{~L} \mathrm{~m}^{-2} \mathrm{~h}^{-1} \mathrm{bar}^{-1}\right)$ & 14.2 \\
\hline Salt permeability $\left(\times 10^{-7} \mathrm{~L} \mathrm{~m}^{-2} \mathrm{~h}^{-1}\right)$ & 0.241 \\
\hline Structure parameter $(\mathrm{m})$ & $310 \times 10^{-3}$ \\
\hline Draw velocity $(\mathrm{m} / \mathrm{s})$ & 0.25 \\
\hline
\end{tabular}

The modeling of the configuration 1 and 2 are investigated in terms of membrane length of each stage and freshwater feed ratio. Precisely, configuration 1 consists of 3 sub-models while configuration 2 consists of 9 sub-models, as demonstrated in Table $2 \mathrm{a}$ and Table $2 b$, respectively. 
Table 2a. Model of configuration 1

\begin{tabular}{|c|c|c|}
\hline Model & Length of $1^{\text {st }}$ stage $(\mathrm{m})$ & Length of $2^{\text {nd }}$ stage (m) \\
\hline 1 & 0.25 & 0.75 \\
\hline 2 & 0.50 & 0.50 \\
\hline 3 & 0.75 & 0.25 \\
\hline
\end{tabular}

Table 2b. Model of configuration b

\begin{tabular}{|c|c|c|c|}
\hline Model & $\begin{array}{c}\text { Length of } 1^{\text {st }} \\
\text { stage }(\mathrm{m})\end{array}$ & $\begin{array}{c}\text { Length of } 2^{\text {nd }} \\
\text { stage }(\mathrm{m})\end{array}$ & $\begin{array}{c}\text { Feed ratio of } \\
\text { the } 1^{\text {st }} \text { stage }\end{array}$ \\
\hline 4 & 0.25 & 0.75 & 0.25 \\
\hline 5 & 0.25 & 0.75 & 0.5 \\
\hline 6 & 0.25 & 0.75 & 0.75 \\
\hline 7 & 0.5 & 0.5 & 0.25 \\
\hline 8 & 0.5 & 0.5 & 0.5 \\
\hline 9 & 0.5 & 0.5 & 0.75 \\
\hline 10 & 0.75 & 0.25 & 0.25 \\
\hline 11 & 0.75 & 0.25 & 0.5 \\
\hline 12 & 0.75 & 0.25 & 0.75 \\
\hline
\end{tabular}

\section{Results and Discussions}

\subsection{Influence of flow ratio $\left(Q_{D} / Q_{F}\right)$ and applied hydraulic pressure in configuration 1}

The effect of flow ratio on power density and water utilization of each stage is studied in a range of 1 to 7 and shown in Figure $3 a-3 d$. The results showed that the power density and water utilization increase with an increase in flow ratio because it provides a high salinity gradient. Also, a high flow ratio decreases the film thickness leading to increased effective concentration. Furthermore, osmotic pressure is high with respect to the high flow ratio. Therefore, the feed solution can be transferred across the membrane more easily. It was found that the flow ratio at 5 is suitable as it offers the optimal power density at the first stage and the second stage at $12.86 \mathrm{~W} / \mathrm{m}^{2}$ and $9.97 \mathrm{~W} / \mathrm{m}^{2}$, respectively. At the suitable flow ratio, water utilization of the first and second stages is $22.29 \%$ and $63.17 \%$, respectively. It can be noticed that the power density of the first stage is greater than the second stage. This finding is caused by the decrease of salinity gradient along the membrane length, leading to reduced osmotic pressure. Oppositely, the water utilization of the second stage is higher than the first one. It implies that the second stage will improve the potential of freshwater utilization. The applied hydraulic pressure also has a strong effect on power density and water flux. When the applied hydraulic pressure is lower than the osmotic pressure, power density is increased while water utilization is decreased. However, water flux is decreased with an increase in applied hydraulic pressure. The suitable applied hydraulic pressure of both stages is 12 bar which is about half of the osmotic pressure.

a
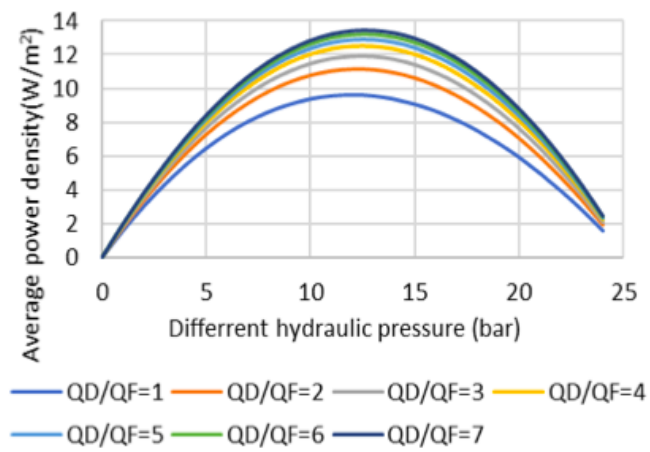

b

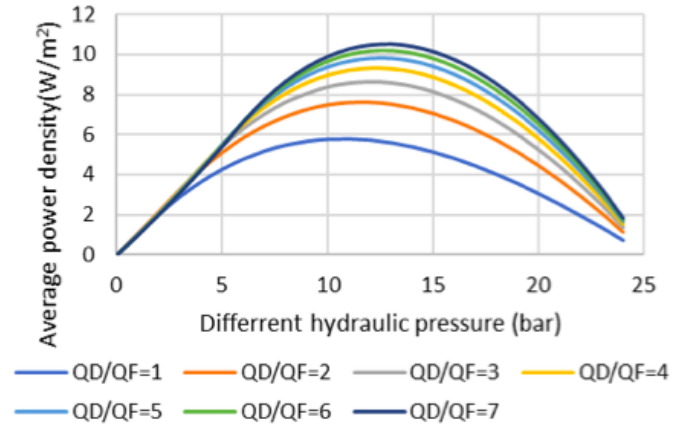

C

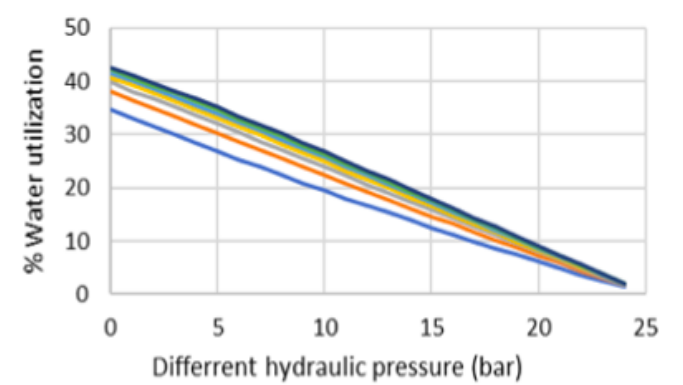

$$
\begin{aligned}
& -\mathrm{QD} / \mathrm{QF}=1-\mathrm{QD} / \mathrm{QF}=2-\mathrm{QD} / \mathrm{QF}=3-\mathrm{QD} / \mathrm{QF}=4 \\
& \mathrm{QD} / \mathrm{QF}=5-\mathrm{QD} / \mathrm{QF}=6-\mathrm{QD} / \mathrm{QF}=7
\end{aligned}
$$

d

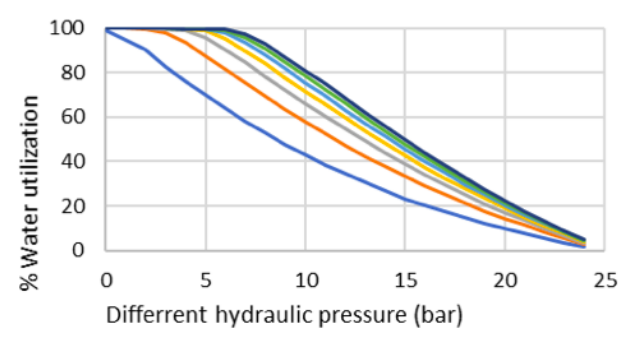

$-\mathrm{QD} / \mathrm{QF}=1$
$\mathrm{QD} / \mathrm{QF}=5-\mathrm{QD} / \mathrm{QF}=2-\mathrm{QD} / \mathrm{QF}=3-\mathrm{QD} / \mathrm{QF}=6-4$
$\mathrm{QD} / \mathrm{QF}=7$

Fig. 3 Effect of flow ratio and hydraulic pressure of the configuration 1 (a) power density of $1^{\text {st }}$ stage (b) power density of $2^{\text {nd }}$ stage (c) water utilization of $1^{\text {st }}$ stage (d) water utilization of $2^{\text {nd }}$ stage 


\subsection{Influence of membrane length in configuration 1}

The effect of membrane length is illustrated in Table 3. When the applied hydraulic pressure is fixed at 12 bar, and the flow ratio is fixed at 5, power density is decreased with an increase in membrane length. For example, when membrane length of the first stage and the second stage is $0.25 \mathrm{~m}$ and $0.75 \mathrm{~m}$, respectively. The power density of the first stage is the highest at 12.86 $\mathrm{W} / \mathrm{m}^{2}$. This is because the ICP and ECP that affect the film thickness on the draw and feed sides are founded. They reduce the effective concentration along membrane length. The $1^{\text {st }}$ stage of model 1 has low water utilization because of low permeation area. On the other hand, the $2^{\text {nd }}$ stage of model 1 has the highest water utilization. According to the result, model 2 offered the highest total power density and total water utilization.

Table 3. Power density and water utilization of Model 1- 3 in Configuration 1

\begin{tabular}{|c|c|c|c|c|}
\hline \multirow{2}{*}{ Model } & \multicolumn{2}{|c|}{ Power density $\left(\mathrm{W} / \mathrm{m}^{2}\right)$} & \multicolumn{2}{c|}{$\%$ Water utilization } \\
\cline { 2 - 5 } & $1^{\text {st }}$ stage & $2^{\text {nd }}$ stage & $1^{\text {st }}$ stage & $2^{\text {nd }}$ stage \\
\hline 1 & 12.86 & 9.97 & 22.29 & 63.17 \\
\hline 2 & 11.47 & 9.93 & 39.01 & 54.74 \\
\hline 3 & 10.57 & 10.39 & 53.55 & 38.26 \\
\hline
\end{tabular}

\subsection{Influence of flow ratio, membrane length and applied hydraulic pressure in Configuration 2}

The effect of membrane length in configuration 2 is similar to configuration 1. Figures 4-6 show the fresh feed ratio of 0.25 with different applied hydraulic pressures and flow ratios. At a low fresh feed ratio (model 1, 4, 7), increasing the membrane length of the $1^{\text {st }}$ stage led to a lower power density but higher water utilization. Water utilization of the $1^{\text {st }}$ stage $(85 \%)$ and the $2^{\text {nd }}$ stage $(67 \%)$ of model 1 are carried out for the same reason as configuration 1. Complete water utilization of the $1^{\text {st }}$ stage is obtained with an increase in membrane length and applied hydraulic pressure. It can be noticed that the result of power density and water utilization showed the opposite trend. This phenomenon leads to an increase in water flux resulting in high power density and water utilization. The volume of feed water that can permeate across the membrane is deficient with high hydraulic pressure, especially at the end of the membrane. However, the optimal applied hydraulic pressure of the $1^{\text {st }}$ stage is higher than a half of osmosis pressure when the membrane length of the $1^{\text {st }}$ stage is longer. For example, the applied hydraulic pressure of 17 bar offered the highest power density of $9.2 \mathrm{~W} / \mathrm{m}^{2}$ (model 4). Applied hydraulic pressure of 18 bars is optimal (model 7). The optimal applied hydraulic pressure of the $2^{\text {nd }}$ stage is 12 bars.
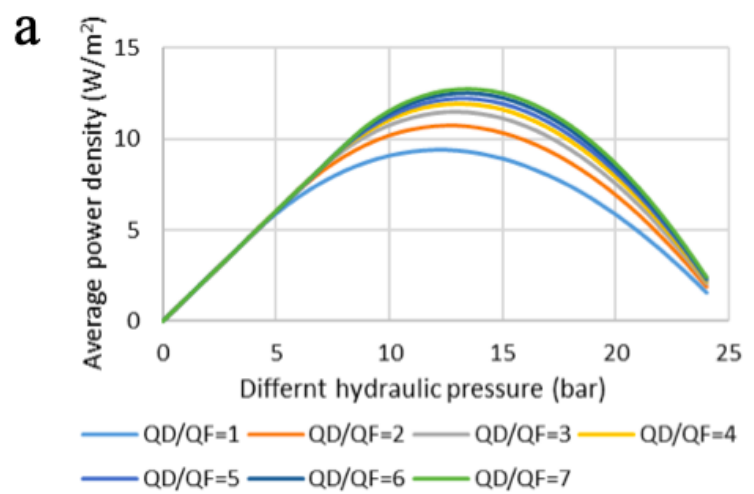

b
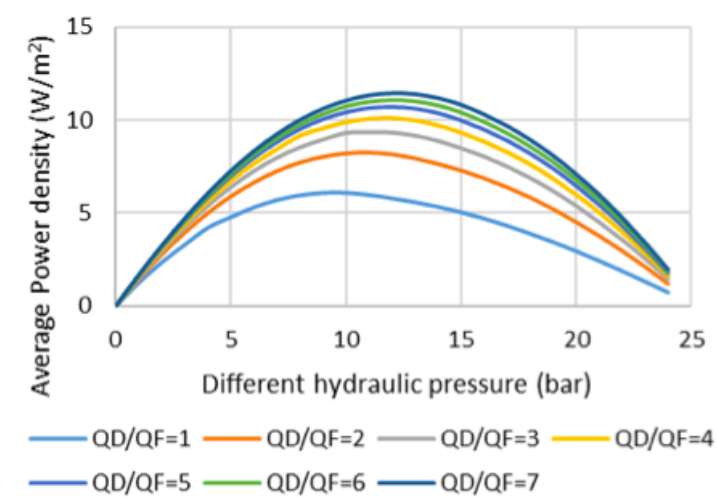

C
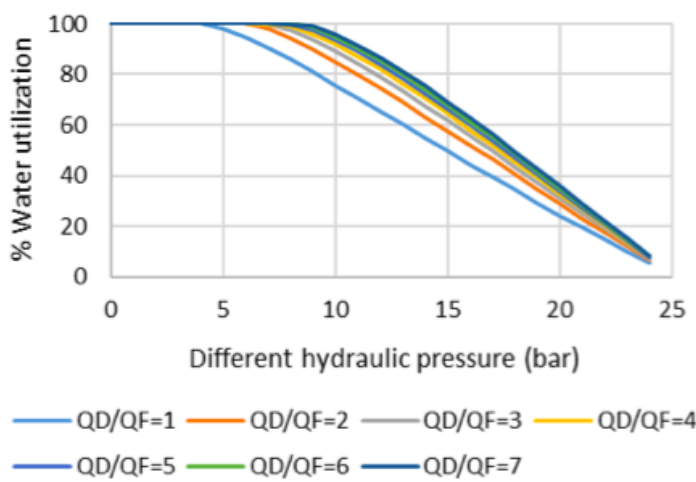

d

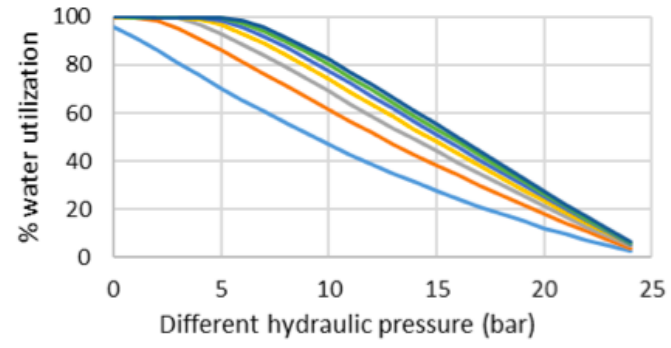

$\begin{array}{rl}-\mathrm{QD} / \mathrm{QF}=1 & \mathrm{QD} / \mathrm{QF}=2-\mathrm{QD} / \mathrm{QF}=3-\mathrm{QD} / \mathrm{QF}=4 \\ \mathrm{QD} / \mathrm{QF}=5 & \mathrm{QD} / \mathrm{QF}=6-\mathrm{QD} / \mathrm{QF}=7\end{array}$

Fig. 4 Model 1 in configuration 2 at fresh feed ratio of 0.25 (a) power density of 1 st stage (b) power density $2^{\text {nd }}$ stage (c) water utilization of 1 st stage (d) water utilization of $2^{\text {nd }}$ stage 
a

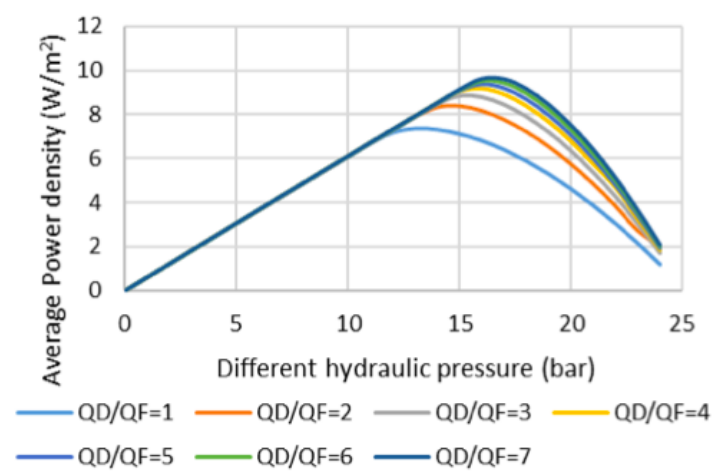

b

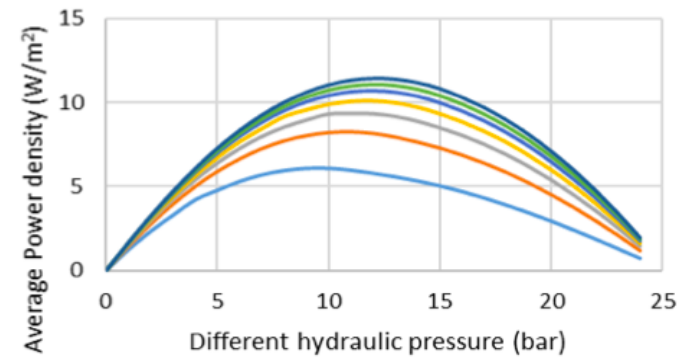

$-\mathrm{QD} / \mathrm{QF}=1-\mathrm{QD} / \mathrm{QF}=2-\mathrm{QD} / \mathrm{QF}=3-\mathrm{QD} / \mathrm{QF}=4$ $-\mathrm{QD} / \mathrm{QF}=5-\mathrm{QD} / \mathrm{QF}=6-\mathrm{QD} / \mathrm{QF}=7$

C
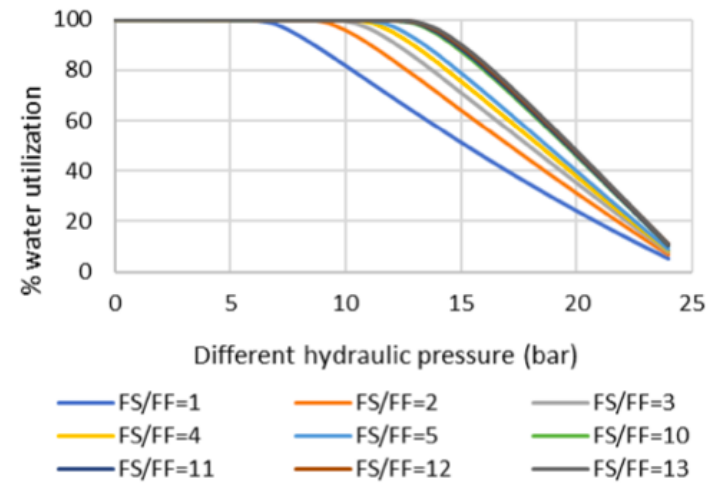

d

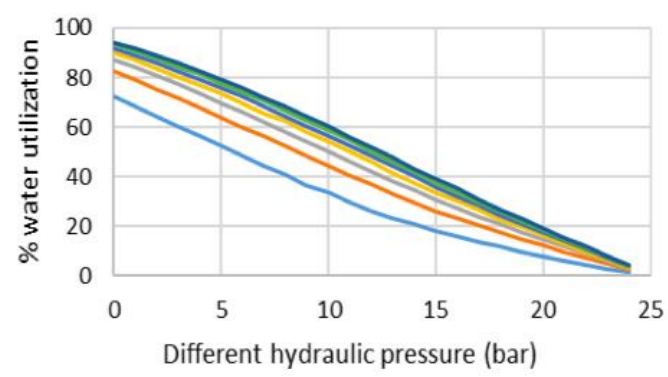

$-\mathrm{QD} / \mathrm{QF}=1-\mathrm{QD} / \mathrm{QF}=2-\mathrm{QD} / \mathrm{QF}=3-\mathrm{QD} / \mathrm{QF}=4$
$-\mathrm{QD} / \mathrm{QF}=5-\mathrm{QD} / \mathrm{QF}=6-\mathrm{QD} / \mathrm{QF}=7$

Fig. 5 Model 4 in configuration 2 at fresh feed ratio of 0.25 (a) power density of 1 st stage (b) power density $2^{\text {nd }}$ stage (c) water utilization of 1 st stage (d) water utilization of $2^{\text {nd }}$ stage

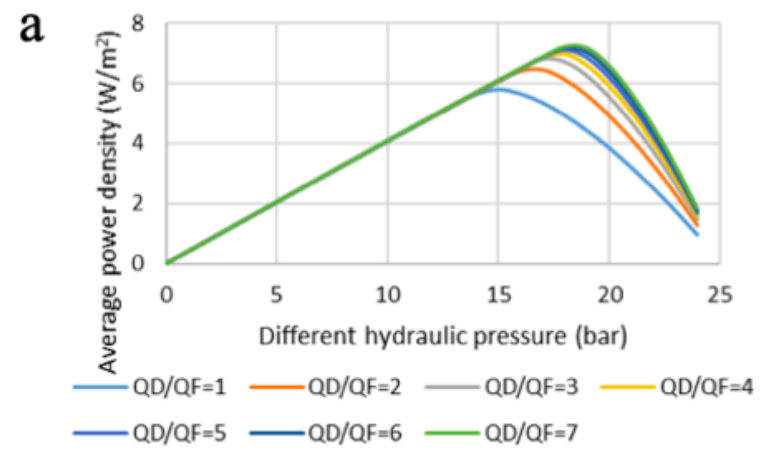

b

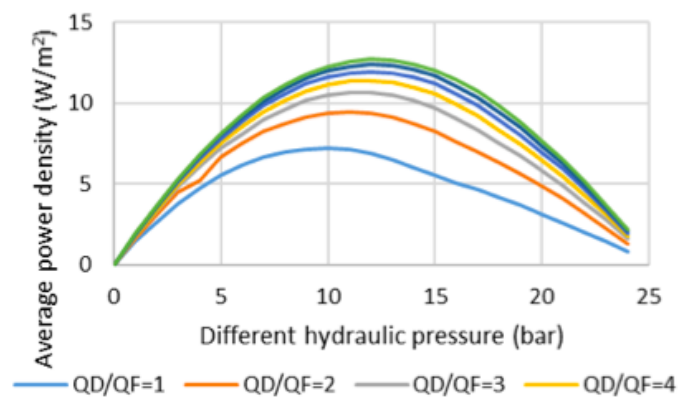

$\mathrm{QD} / \mathrm{QF}=1-\mathrm{QD} / \mathrm{QF}=2-\mathrm{QD} / \mathrm{QF}=3-\mathrm{QD} / \mathrm{QF}=4$
$\mathrm{QD} / \mathrm{QF}=5-\mathrm{QD} / \mathrm{QF}=6-\mathrm{QD} / \mathrm{QF}=7$

C

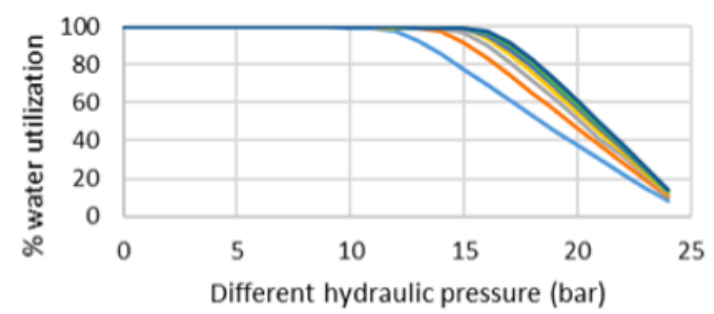

$\longrightarrow \mathrm{QD} / \mathrm{QF}=1-\mathrm{QD} / \mathrm{QF}=2-\mathrm{QD} / \mathrm{QF}=3-\mathrm{QD} / \mathrm{QF}=4$

$\longrightarrow \mathrm{QD} / \mathrm{QF}=5-\mathrm{QD} / \mathrm{QF}=6-\mathrm{QD} / \mathrm{QF}=7$

d
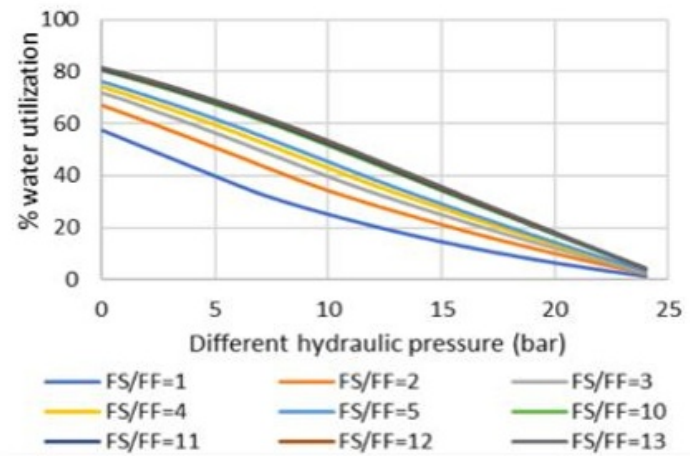

Fig. 6 Model 7 in configuration 2 at fresh feed ratio of 0.25 (a) power density of 1 st stage (b) power density $2^{\text {nd }}$ stage (c) water utilization of 1 st stage (d) water utilization of $2^{\text {nd }}$ stage 


\subsection{Influence of fresh feed ratio in configuration 2}

Tables 4-6 show the power density and water utilization at a fixed flow ratio of 5 and applied hydraulic pressure of 12 bars. In this work, the fresh feed ratio is varied when draw velocity is fixed. An increase in fresh feed ratio resulted in high power density and water utilization. Because an increase in fresh feed ratio causes a high feed velocity, film thickness on the feed side is decreased, leading to high water flux. To consider models 4 to 6 in configuration 2 , the power density of the $1^{\text {st }}$ stage is greater than the $2^{\text {nd }}$ stage. However, the power density of the $1^{\text {st }}$ stage of models 7 to 12 is lower than those of the $2^{\text {nd }}$ stage. It is because the $1^{\text {st }}$ stage of models 4 to 6 has a shorter membrane length. The fresh feed ratio also influenced water utilization. Thus, the lower fresh feed ratio leads to higher water utilization of the $1^{\text {st }}$ stage than the $2^{\text {nd }}$ stage (model 4, 7, 10). However, membrane length substantially impacted water utilization, especially at medium and high fresh feed ratios. When comparing configuration 1 and configuration 2 , it can be seen that the average power density of both configurations is similar. The insight behavior shows that film thickness and feeds velocity at the feed side slightly affect power density. The Configuration 1 and Configuration 2 can provide the average water utilization $43 \%$ and $78 \%$, respectively. So The Configuration 2 offer more benefits than the Configuration 1. It is because the fresh feed ratio increases the salinity gradient, so water transport is driven. The best conditions of Configuration 2 are fresh feed ratio of 0.25, membrane length of $1^{\text {st }}$ stage of $0.25 \mathrm{~m}$, and membrane length of $2^{\text {nd }}$ stage of $0.75 \mathrm{~m}$. They offered the highest water utilization. To compared with the reported literature [9], the two - stage PRO can provide higher power density than commercial single stage PRO (6.5 $\mathrm{W} / \mathrm{m}^{2}$ ). This is because two-stage PRO improve salinity gradient. The results of this work is similar to $\mathrm{He}$ et al. [7] which confirmed that two-stage PRO, divided feed solution performed the better performance in term of average power density. Although adding the second stage does not improve power generation significantly when fresh feed water is used. The two-stage PRO will important when feed brine is used in the first-stage PRO and replacement the fresh solution in the second - stage PRO [10].

Table 4. Power density and water utilization of model 4- 5 (short membrane length of $1^{\text {st }}$ stage) in configuration 2

\begin{tabular}{|c|c|c|c|c|}
\hline \multirow{2}{*}{ Model } & \multicolumn{2}{|c|}{ Power density $\left(\mathrm{W} / \mathrm{m}^{2}\right)$} & \multicolumn{2}{c|}{$\%$ water utilization } \\
\cline { 2 - 5 } & $1^{\text {st }}$ stage & $2^{\text {nd }}$ stage & $1^{\text {st }}$ stage & $2^{\text {nd }}$ stage \\
\hline 4 & 12.26 & 9.89 & 89 & 66.99 \\
\hline 5 & 12.73 & 9.47 & 44.04 & 94.38 \\
\hline 6 & 12.83 & 5.53 & 29.61 & 99.23 \\
\hline
\end{tabular}

Table 5. Power density and water utilization of model 7- 9 (medium membrane length of $1^{\text {st }}$ stage) in configuration 2

\begin{tabular}{|c|c|c|c|c|}
\hline \multirow{2}{*}{ Model } & \multicolumn{2}{|c|}{ Power density $\left(\mathrm{W} / \mathrm{m}^{2}\right)$} & \multicolumn{2}{c|}{$\%$ water utilization } \\
\cline { 2 - 5 } & $1^{\text {st }}$ stage & $2^{\text {nd }}$ stage & $1^{\text {st }}$ stage & $2^{\text {nd }}$ stage \\
\hline 7 & 7.92 & 10.58 & 97.37 & 48.39 \\
\hline 8 & 10.13 & 10.13 & 75.64 & 69 \\
\hline 9 & 11.39 & 7.91 & 51.62 & 99.36 \\
\hline
\end{tabular}

Table 6. Power density and water utilization of model 10- 12 (high membrane length of $1^{\text {st }}$ stage) in configuration 2

\begin{tabular}{|c|c|c|c|c|}
\hline \multirow{2}{*}{ Model } & \multicolumn{2}{|c|}{ Power density $\left(\mathrm{W} / \mathrm{m}^{2}\right)$} & \multicolumn{2}{c|}{$\%$ water utilization } \\
\cline { 2 - 5 } & $1^{\text {st }}$ stage & $2^{\text {nd }}$ stage & $1^{\text {st }}$ stage & $2^{\text {nd }}$ stage \\
\hline 10 & 5.7 & 11.88 & 98.35 & 27.66 \\
\hline 11 & 9.85 & 11.05 & 97.38 & 38.56 \\
\hline 12 & 10.43 & 10.69 & 70.4 & 73.98 \\
\hline
\end{tabular}

\section{Conclusion}

The performance analysis of two-stage PRO (i.e., twostage PRO in series with no feed interstage and twostage PRO in series with feed interstage) is investigated in terms of power density and water utilization. The two-stage PRO in series with feed interstage is preferred because it can save freshwater requirements. The best condition is fresh feed ratio of 0.25 , membrane length of $1^{\text {st }}$ stage of $0.25 \mathrm{~m}$, the flow ratio of 5, and applied hydraulic pressure of 12 bar (model 1).

\section{Acknowledgment}

The authors would like to acknowledge the support from King Mongkut's University of Technology North Bangkok fund (KMUTNB-60-GEN-050).

\section{References}

1. A. Altaee, A. Sharif. Desalination 356, 31-46 (2015).

2. W. A. Phillip, J.S. Yong, M. Elimelech. Environmental Science \& Technology Journals. 44, $5170-5176$ (2010).

3. I.L. Alsvik, M.-B. Hagg. Polymers, 5, 303-327 (2013).

4. W.Y. Chia, S.R. Chia, K.S. Khoo, K.W. Chew, P. L. Show. Journal of Water Process Engineering. 39, 101758 (2021). 
5. A. Achili, J.L. Prantle, N.T. Hancock, E.B. Maxwell, A.E. Childress. Environmental Science \& Technology Journals. 48, 6437-6443 (2014).

6. M.F. Naguib, J. Maisonneuve, C.B. Laflamme, P. Pillay. Renew. Energy. 76, 619 - 627 (2015).

7. W. He, Y. Wang, M. Shaheed. Desalination 359, $186-199$ (2015).
8. H. Chung, J. Saminathan, J. Lienhard. Desalination 476, 114230 (2020).

9. N. Sawaki, C. Chen. Desalination 497, 114767 (2021).

10. A. Alaneza, A. Altaee. Energy Procedia- Journals. 142, 4182 - 4197 (2017) 